\author{
Marquette University \\ e-Publications@Marquette
}

$10-10-2013$

\title{
Conditional Spectrum-Based Ground Motion Selection. Part I: Hazard Consistency for Risk-Based Assessments
}

Ting Lin

Marquette University, ting.lin@marquette.edu

Curt B. Haselton

California State University - Chico

Jack W. Baker

Stanford University

Follow this and additional works at: https://epublications.marquette.edu/civengin_fac

Part of the Civil and Environmental Engineering Commons

\section{Recommended Citation}

Lin, Ting; Haselton, Curt B.; and Baker, Jack W., "Conditional Spectrum-Based Ground Motion Selection. Part I: Hazard Consistency for Risk-Based Assessments" (2013). Civil and Environmental Engineering Faculty Research and Publications. 11.

https://epublications.marquette.edu/civengin_fac/11 


\title{
Conditional Spectrum-Based Ground Motion Selection. Part I: Hazard Consistency for Risk-Based Assessments
}

\author{
Ting Lin \\ Department of Civil and Environmental Engineering \\ Stanford University \\ Stanford, CA \\ Curt B. Haselton \\ Department of Civil Engineering \\ California State University, Chico \\ Chico, CA \\ Jack W. Baker \\ Department of Civil and Environmental Engineering \\ Stanford University \\ Stanford, CA
}

Summary: The conditional spectrum (CS, with mean and variability) is a target response spectrum that links nonlinear dynamic analysis back to probabilistic seismic hazard analysis for ground motion selection. The CS is computed on the basis of a specified conditioning period, whereas structures under consideration may be sensitive to response spectral amplitudes at multiple periods of excitation. Questions remain regarding the appropriate choice of conditioning period when utilizing the CS as the target spectrum. 
NOT THE PUBLISHED VERSION; this is the author's final, peer-reviewed manuscript. The published version may be accessed by following the link in the citation at the bottom of the page.

This paper focuses on risk-based assessments, which estimate the annual rate of exceeding a specified structural response amplitude. Seismic hazard analysis, ground motion selection, and nonlinear dynamic analysis are performed, using the conditional spectra with varying conditioning periods, to assess the performance of a 20-story reinforced concrete frame structure. It is shown here that risk-based assessments are relatively insensitive to the choice of conditioning period when the ground motions are carefully selected to ensure hazard consistency. This observed insensitivity to the conditioning period comes from the fact that, when CS-based ground motion selection is used, the distributions of response spectra of the selected ground motions are consistent with the site ground motion hazard curves at all relevant periods; this consistency with the site hazard curves is independent of the conditioning period. The importance of an exact CS (which incorporates multiple causal earthquakes and ground motion prediction models) to achieve the appropriate spectral variability at periods away from the conditioning period is also highlighted. The findings of this paper are expected theoretically but have not been empirically demonstrated previously.

\section{Introduction}

Ground motion selection provides the necessary link between seismic hazard and structural response. It determines ground motion input for a structure at a specific site for nonlinear dynamic analysis. As nonlinear dynamic analysis becomes more common in research and practice, there is an increased need for clear guidance on appropriate ground motion selection methods. Ground motion selection has a significant impact on conclusions regarding structural safety, because ground motion uncertainty contributes significantly to uncertainty in structural analysis output. To select representative ground motions to effectively assess the future reliability of a structure at a given location, it is important to ensure hazard consistency of ground motion inputs and evaluate structural response by using a risk-based approach.

Earthquake-induced structural response depends on the characteristics of both the ground motion hazard and the structure. If hazard consistency is ensured, then results from the corresponding structural analysis would be meaningful. Risk-based assessment of structural response estimates the mean annual rate of exceeding a specified structural response amplitude or an engineering demand parameter, EDP. This calculation is also often referred to as the first step of the 'PEER Integral' [1] ], a 'drift hazard' calculation [2] , or a 'time-based assessment' [3] . It differs from intensity-based

Earthquake Engineering \& Structural Dynamics, Vol. 42, No. 12 (October 10, 2013): pg. 1847-1865. DOI. This article is (C) Wiley and permission has been granted for this version to appear in e-Publications@Marquette. Wiley does not grant permission for this article to be further copied/distributed or hosted elsewhere without the express permission from Wiley. 
assessment, which only considers structural response amplitude at a given ground motion intensity level. It is obtained using full distributions of structural response for ground motions at each given intensity and considers multiple intensity levels, along with their occurrence rates. The conclusions drawn depend on the type of assessment performed. This paper focuses on risk-based assessment, whereas the companion paper [4] additionally considers intensitybased assessment.

Ground motion selection is often associated with a target response spectrum. Recent work has illustrated that scaling up arbitrarily selected ground motions to a specified spectral acceleration (Sa) level at vibration period (or 'period', for brevity in lieu of 'vibration period') $T$ can produce overly conservative structural responses, because a single extreme Sa $(T)$ level of interest for engineering analysis does not imply occurrence of equally extreme Sa levels at all periods [ㄷ]. The 'conditional mean spectrum' (CMS) and 'conditional spectrum' (CS) have been developed to describe the expected response spectrum associated with a ground motion having a specified Sa ( $T$ ) level e.g., [5-7]. The CMS for a rare (i.e., large positive $\epsilon$ ) Sa $(T)$ level has a relative peak at $T$ and tapers back toward the median spectrum for the considered causal scenario event at other periods. The CS differs from the CMS only in that it also considers the variability in response spectra at periods other than the conditioning period (which by definition has no variability). The CS (with mean and variance) is a target spectrum that links ground motion hazard to structural response. A computationally efficient algorithm has been developed for selecting ground motions to match this target spectrum mean and variance []․ Alternatively, a generalized conditional intensity measure approach that considers intensity measures other than Sa can be used if non-spectral ground motion parameters are also deemed important for predicting the EDP of interest [9-11].

The CS is computed on the basis of a specified conditioning period (denoted here as $T^{*}$ ), whereas structures under consideration generally have responses that are sensitive to excitation at a range of periods, including both higher-mode periods and 'lengthened periods' associated with nonlinear behavior [12]. A structure's first-mode period $\left(T_{1}\right)$ is often chosen as $T^{*}$ to calculate peak story drift ratio (PSDR, i.e., the maximum story drift ratio (SDR) observed over all 
stories, over the duration of shaking) - this is carried out because $\mathrm{Sa}\left(T_{1}\right)$ is often a 'good' predictor of that EDP for low-rise or mid-rise buildings, so scaling ground motions based on $\mathrm{Sa}\left(T_{1}\right)$ can lead to reduced scatter in resulting response predictions and thus minimizes the required number of nonlinear dynamic analyses [13]. There are, however, circumstances under which the EDP of interest is not dominated by the first-mode period, e.g., peak floor acceleration (PFA, i.e., maximum acceleration observed over all floors including the ground, over the duration of shaking). Furthermore, when the structural design is not yet finalized, it is difficult to identify a single conditioning period. Questions remain regarding the appropriate choice of conditioning period when utilizing the CS as the target spectrum. This paper investigates the effect of conditioning period on risk-based structural response assessments and the significance of hazard consistency in ground motion inputs. The methodology to perform ground motion selection and structural analysis is presented, and an illustrative example is used where appropriate.

Section 2 'Conditional spectrum-based ground motion selection' outlines the procedures for seismic hazard analysis and deaggregation, target spectrum computation, and ground motion selection to match target spectrum. Next, Section 3 'Hazard consistency of ground motion response spectra' compares distributions of selected ground motion response spectra with the target seismic hazard curves and shows how to make adjustments to the target spectra to ensure hazard consistency, when necessary. Last, structural analyses are carried out in Section 4 to perform a risk-based assessment for PSDR. Such nonlinear dynamic analyses are repeated using ground motions matching the CS at various conditioning periods, to examine the impact of conditioning period; ground motions are also reselected to examine the significance of hazard consistency. Analyses for additional EDPs are then conducted in Section 5 to illustrate and confirm the generality of the procedures and findings.

The primary illustrative structure considered is a 20-story reinforced concrete special moment frame located at Palo Alto, California, with the perimeter frame designed to resist lateral forces. This building was designed for the recent FEMA P695 project $[\underline{14}, 15]$ and is denoted Building 1020 in that study. It is a two-dimensional model in [16], with strength deterioration (both cyclic and in-cycle) 
and stiffness deterioration. The first three elastic modal periods are 2.6, 0.85, and $0.45 \mathrm{~s}$. The building was designed per the IBC 2003 [17], for a site with a slightly lower design ground motion level than the site being utilized in this study (by approximately $20 \%$ ). This structure is analyzed using ground motions selected to match the CS conditioned on various periods of interest. These conditioning periods include the first-mode period, $T_{1}$, the higher-mode (second-mode and third-mode) periods, $T_{2}$ and $T_{3}$, and a lengthened period due to nonlinearity, $2 T_{1}$. Although a generic lengthened period is used for this structure and others, it is not necessarily the best period for nonlinear response as the lengthened period is structure specific. These periods are used to illustrate the range of conditioning periods that may be of interest (the specific conditioning period used can be any period) and show the sensitivity of structural response results (e.g., PSDR and PFA) with respect to this range of conditioning periods.

\section{Conditional Spectrum-Based Ground Motion Selection}

Procedures for ground motion selection based on a target spectrum are presented as follows: first, seismic hazard analysis is performed for the site and period of interest, and deaggregation is performed to identify the ground motion characteristics (such as magnitude, distance, and $\epsilon$ ) that contributed to occurrence of a specified ground motion intensity level; next, a target spectrum is computed using the deaggregation information and relevant ground motion prediction models (GMPMs); and finally, ground motions are selected from a ground motion database to match the specified target spectrum.

\subsection{Seismic hazard analysis and deaggregation}

Probabilistic seismic hazard analysis is used to estimate the seismic hazard rate at any site for a period of interest. Given a site location and an associated soil condition, the annual rate of $\mathrm{Sa}$ exceedance at a period of vibration $\left(T^{*}\right), \mathrm{Sa}\left(T^{*}\right)$, can be obtained from PSHA computation software such as the United States Geological Survey (USGS) web tool at https://geohazards.usgs.gov/deaggint/2008/. The period of interest, 
$T^{*}$, often corresponds to a structure's first-mode period of vibration, $T_{1}$, but can also be another period such as a higher-mode period, a lengthened period, or any other period. The annual rate of Sa exceedance can be expressed in terms of return period, and the Sa amplitude is often referred to as an 'intensity level'. For instance, an intensity level with $2 \%$ in 50 -year exceedance rate corresponds to an Sa value with a return period of 2475 years under a Poissonian assumption of ground motion occurrence.

For a specified intensity level, deaggregation is used to identify the characteristics associated with the occurrence of given ground motion intensity levels, such as magnitude $(M)$, distance $(R)$, and $\varepsilon$. This can be the full conditional distribution of $M, R$, and $\epsilon$, or their mean values. Such deaggregation information can also be obtained from PSHA computation software such as the USGS web tool. In cases where results for the period of vibration $\left(T^{*}\right)$ or exceedance rate of interest cannot be obtained directly from PSHA computation software, interpolation can be used for intermediate values of interest.

To illustrate, we obtain a seismic hazard curve and deaggregation for a site located in Palo Alto, California, with a shear wave velocity in the top $30 \mathrm{~m}$ of the soil, $V_{S 30}$, of $400 \mathrm{~m} / \mathrm{s}$. By assuming that a period of $2.6 \mathrm{~s}$ (which corresponds to the first-mode period of vibration, $T_{1}$, for the example 20-story structure) is of interest, the seismic hazard curve for $\mathrm{Sa}$ at this period, $\mathrm{Sa}(2.6 \mathrm{~s})$, is plotted in Figure $1(\mathrm{a})$. As the ground motion intensity, $\mathrm{Sa}(2.6 \mathrm{~s})$, increases, the annual rate of exceedance decreases. The $\mathrm{Sa}(2.6 \mathrm{~s})$, which is associated with $2 \%$ in 50 -year probability of exceedance (an annual rate of 0.0004 ), can be identified through the hazard curve as $\mathrm{Sa}(2.6 \mathrm{~s})=0.45 \mathrm{~g}$. Deaggregation can also be obtained to identify the causal $M, R$, and $\epsilon$ values, as shown in Figure 1 (b), both as histograms and mean values. The tallest column in such figures corresponds to the range of the $M / R / \epsilon$ combination with the highest contribution to seismic hazard at the site.

\subsection{Target spectrum computation}

On the basis of the deaggregation information, a target spectrum can be computed using relevant GMPMs e.g., [18-20]. From

Earthquake Engineering \& Structural Dynamics, Vol. 42, No. 12 (October 10, 2013): pg. 1847-1865. DOI. This article is (C) Wiley and permission has been granted for this version to appear in e-Publications@Marquette. Wiley does not grant permission for this article to be further copied/distributed or hosted elsewhere without the express permission from Wiley. 
the previous section, the target $\mathrm{Sa}$ at period $T^{*}, \mathrm{Sa}\left(T^{*}\right)$, is obtained from PSHA, and its associated mean causal earthquake magnitude $(M)$ and distance $(R)$ are obtained from deaggregation. Now, a GMPM can be used to obtain the logarithmic mean and standard deviation of Sa at all periods $T_{i}$, denoted as $\mu_{\mathrm{lnSa}}\left(M, R, T_{i}\right)$ and $\sigma_{\mathrm{lnSa}}\left(M, T_{i}\right)$. For the target $\mathrm{Sa}\left(T^{*}\right)$ value, compute the target $\epsilon\left(T^{*}\right)$, the number of standard deviations by which $\operatorname{lnSa}\left(T^{*}\right)$ differs from the mean prediction $\mu_{\text {InSa }}\left(M, R, T^{*}\right)$, at $T^{*}$.

$$
\varepsilon\left(T^{*}\right)=\frac{\ln \mathrm{Sa}\left(T^{*}\right)-\mu_{\ln \mathrm{Sa}}\left(M, R, T^{*}\right)}{\sigma_{\ln \mathrm{Sa}}\left(M, T^{*}\right)}
$$

This $\epsilon\left(T^{*}\right)$ value can also be obtained directly from deaggregation.

For a uniform hazard spectrum (UHS) associated with an annual rate of exceedance (which is uniform across all periods), Sa values at various periods $T_{i}$ can be obtained directly from PSHA hazard curves for periods $T_{i}$ associated with the given annual rate of exceedance.

The CMS utilizes correlation across periods to estimate the expected Sa values at all periods $T_{i}\left(\mathrm{Sa}\left(T_{i}\right)\right)$, given the target Sa value at the period of interest $T^{*}\left(\mathrm{Sa}\left(T^{*}\right)\right)$ e.g., $[5,6,21,22]$. For the CMS, $\epsilon\left(T_{i}\right)$ is not the same as $\epsilon\left(T^{*}\right)$. Additional information regarding the correlation coefficient between pairs of $\varepsilon$ values at two periods, $\rho\left(\epsilon\left(T_{i}\right), \epsilon\left(T^{*}\right)\right)$ (hereinafter referred to as $\left.\rho\left(T_{i}, T^{*}\right)\right)$ e.g., from [23] is needed to compute the conditional mean $\mathrm{Sa}$ at other periods

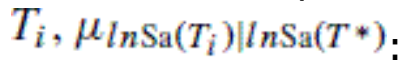

$$
\mu_{l n \mathrm{Sa}\left(T_{i}\right) \mid \ln \mathrm{Sa}\left(T^{*}\right)}=\mu_{\ln \mathrm{Sa}}\left(M, R, T_{i}\right)+\rho\left(T_{i}, T^{*}\right) \varepsilon\left(T^{*}\right) \sigma_{l n \mathrm{Sa}}\left(M, T_{i}\right)(2)
$$

Similarly, the conditional standard deviation of Sa at period $T_{i}$, $T_{i}, \sigma_{\ln \mathrm{Sa}\left(T_{i}\right) \mid \ln \mathrm{Sa}\left(T^{*}\right)}$, can be computed as

$$
\sigma_{\ln \mathrm{Sa}\left(T_{i}\right) \mid \ln \mathrm{Sa}\left(T^{*}\right)}=\sigma_{\ln \mathrm{Sa}}\left(M, T_{i}\right) \sqrt{1-\rho^{2}\left(T_{i}, T^{*}\right)}
$$

The conditional standard deviation $\sigma_{\ln \mathrm{Sa}\left(T_{i}\right) \mid \ln \mathrm{Sa}\left(T^{*}\right)}$ from Equation (3), when combined with the conditional mean value $\mu_{\ln \mathrm{Sa}\left(T_{i}\right) \mid \ln \mathrm{Sa}\left(T^{*}\right)}$ from Equation (2), specifies a distribution of Sa values 
at all periods (where the distribution at a given period is Gaussian, as justified by Jayaram and Baker. [24]). The resulting spectrum distribution is termed CS, to be distinguished from the CMS that does not consider the variability specified by Equation (3).

Mean values of $M, R, \epsilon$ from deaggregation, and a single GMPM can be used to compute an approximate CS. Probabilistic seismic hazard analysis, however, utilizes multiple GMPMs to come up with the hazard estimates, whereas deaggregation shows that a range of $M, R$, and $\epsilon$ contributed to any given $\mathrm{Sa}\left(T^{*}\right)$. An exact computation of the CS mean and standard deviation that incorporates multiple causal earthquakes and multiple GMPMs is documented in [7] . For practical use to select ground motions, the exact mean and standard deviation can be combined with a lognormal distribution assumption. The exact CMS can also be obtained from the USGS web tool. Alternatively, Bradley [9] extends the concept of the CMS to develop the generalized conditional intensity measures and computes the exact distribution [9] ,Equation (8), which has implications for ground motion selection as elaborated upon by Bradley [10], although at present, that approach has not considered the impact of multiple GMPMs in hazard analysis. The exact CS does not change the conditional mean significantly but increases the conditional standard deviation, especially for periods away from the conditioning period []], as will be discussed further.

In the illustrative example, the CS, which includes both mean and variability, is computed for 10 intensity levels at four periods of interest, by using Equations (2) and (3). The 10 intensity levels of $\mathrm{Sa}\left(T^{*}\right)$ were chosen to correspond to specified probabilities of exceedance ranging from $50 \%$ in 30 years to $1 \%$ in 200 years (the range that is provided by USGS), and the periods of interest, $T^{*}$, correspond to the first three modal periods $(2.6,0.85$, and $0.45 \mathrm{~s})$ of the structure and a lengthened period ( $5 \mathrm{~s}$ ) that is associated with nonlinear behavior. To obtain an approximate CS, we obtain mean deaggregation values of magnitude, $M$, and distance, $R$, given each $\mathrm{Sa}\left(T^{*}\right)$ from the USGS deaggregation web tool and used as inputs to Equations (2) and (3). Other relevant parameters, such as the depth to the top of rupture, are inferred for the rupture that dominates the hazard at the site considered here. A single GMPM [19] , in this case is used to obtain the logarithmic mean and standard deviation, 
$\mu_{\text {InSa }}\left(M, R, T_{i}\right)$ and $\sigma_{\text {InSa }}\left(M, T_{i}\right)$. The target $\epsilon\left(T^{*}\right)$ is back-calculated using Equation (1). The correlation coefficient between pairs of $\epsilon$ values at two periods, $\rho\left(T_{i}, T^{*}\right)$, is obtained from [23]. These inputs are then used to compute the CS with Equations (2) and (3).

The conditional mean spectra (using Equation (2) alone) for these intensity levels and periods of interest are shown in Figure $\underline{2}$ (a) and (b). As the intensity level increases, the deaggregated mean $\epsilon$ value increases, and the spectral shape of the CMS becomes more peaked at the conditioning period, as illustrated in Figure $\underline{2}(\mathrm{a})$. For an Sa amplitude associated with $2 \%$ in 50 years, Sa exceedance, the UHS, superimposed on the CMS at various periods, is an envelope of all the CMS, as illustrated in Figure $\underline{2}(\mathrm{~b})$. The Sa values of the CMS at their respective conditioning periods equal those of the UHS.

\subsection{Ground motion selection to match target spectrum}

With the target spectra identified and computed, ground motions can then be selected from a ground motion database to match each target spectrum. Suites of ground motions can be selected and scaled such that they collectively match the entire distribution of the $\mathrm{CS}$, by using a computationally efficient algorithm [ $\underline{8}]$. With this publicly available software (http://www.stanford.edu/ bakerjw/gm\selection.html), the user provides a target spectrum or deaggregation information, along with any desired limitations on such parameters as magnitude, distance, site condition, and scale factor, and the software produces selected and scaled ground motions from the PEER NGA database [25] .

To illustrate, Figure $\underline{3}$ shows the response spectra of 40 ground motions selected and scaled to match the CS (mean and standard deviation) via [] $]$ with Sa(2.6s) having $2 \%$ in 50 -year probability of exceedance. Both linear and logarithmic scale plots are presented to orient the reader familiar with either format. The same procedure was repeated to select ground motions for all other intensity levels and periods described.

\section{Hazard Consistency of Ground Motion Response Spectra}

Earthquake Engineering \& Structural Dynamics, Vol. 42, No. 12 (October 10, 2013): pg. 1847-1865. DOI. This article is (C) Wiley and permission has been granted for this version to appear in e-Publications@Marquette. Wiley does not grant permission for this article to be further copied/distributed or hosted elsewhere without the express permission from Wiley. 
Once ground motions are selected for all intensity levels and periods, distributions of selected ground motion response spectra can be computed and compared with the target seismic hazard curves to check hazard consistency. Hazard consistency implies that the distributions of response spectra from the selected ground motions (through the CS as the target spectrum) are consistent with the site ground motion hazard curves at all relevant periods. In theory, the use of the exact CS results in consistent rates of exceedance between the selected ground motion response spectra and the target seismic hazard curves. If an approximate CS is used and the resulting ground motion response spectra do not match well with the target seismic hazard curve, adjustments in the logarithmic standard deviation of the target CS may need to be made, and ground motions are reselected prior to structural analysis.

\subsection{Linking ground motion response spectra to seismic hazard}

The ground motion selection procedure, as illustrated in Figure $\underline{3}$, is used for 10 intensity levels (where the mean and standard deviation of the selected ground motions' response spectra are consistent with those of the target CS at each intensity level), and the response spectra of the selected ground motions (with a total of 400 ground motions) at each conditioning period can be plotted. In Figure $\underline{4}(a)$ and (b), we see the response spectra of the ground motions selected and scaled to match the specific values that the spectra are conditioned upon, $\mathrm{Sa}(2.6 \mathrm{~s})$ and $\mathrm{Sa}(0.85 \mathrm{~s})$; we see the 'pinched' shapes of the spectra at 2.6 and $0.85 \mathrm{~s}$ in Figure $\underline{4}$ (a) and (b), respectively, because only $10 \mathrm{Sa}\left(T^{*}\right)$ amplitudes were used here. At other periods, the spectra are more varied, as the amplitudes at other periods have variability even when $\mathrm{Sa}\left(T^{*}\right)$ is known with certainty. But these ground motions were selected to maintain proper conditional means and variances, ensuring that the distributions of spectra at all periods are still consistent with all known hazard information for the site being considered. It is difficult to evaluate this consistency by simply counting the number of ground motions exceeding a given spectral amplitude, because there are 40 ground motions at each Sa amplitude, whereas the real site will have many more low-amplitude ground motions than high-amplitude motions.

Earthquake Engineering \& Structural Dynamics, Vol. 42, No. 12 (October 10, 2013): pg. 1847-1865. DOI. This article is (C) Wiley and permission has been granted for this version to appear in e-Publications@Marquette. Wiley does not grant permission for this article to be further copied/distributed or hosted elsewhere without the express permission from Wiley. 
To make a quantitative evaluation of the 'hazard consistency' of the selected ground motions' response spectra at an arbitrary period $T$, we compute the rate of exceedance of $\mathrm{Sa}(T)$ implied by the ground motions selected conditional on $\mathrm{Sa}\left(T^{*}\right)$ by using the following equation:

$$
\lambda(\mathrm{Sa}(T)>y)=\int_{x} P\left(\mathrm{Sa}(T)>y \mid \mathrm{Sa}\left(T^{*}\right)=x\right) \mid d \lambda\left(\mathrm{Sa}\left(T^{*}\right)>x \mid\right.
$$

where $P\left(\mathrm{Sa}(T)>y \mid \mathrm{Sa}\left(T^{*}\right)=x\right)$ is the probability that a ground motion selected and scaled to have $\mathrm{Sa}\left(T^{*}\right)=x$ has an $\mathrm{Sa}$ at period $T$ that is greater than $y$. Here, this probability is estimated as simply the fraction of the 40 ground motions with $\mathrm{Sa}\left(T^{*}\right)=x$ that have $\mathrm{Sa}(T)>y$. The multiplication of these probabilities by the derivative of the hazard curve for $\mathrm{Sa}\left(T^{*}\right)$ reweights the results according to the predicted rate of observing ground motions with $\mathrm{Sa}\left(T^{*}\right)=x$.

Figure $\underline{4}(\mathrm{c})$ shows the computed rate of ground motions with $\mathrm{Sa}(2.6 \mathrm{~s})>y$ for each set of selected motions (the two in Figure 4 (a) and (b) plus the sets selected on the basis of $T^{*}=0.45 \mathrm{~s}$ and $T^{*}$ $=5.0 \mathrm{~s}$ ). Also shown for reference is the 'direct hazard curve' for $\mathrm{Sa}(2.6 \mathrm{~s})$ obtained from seismic hazard analysis. Ideally, the selected ground motions would be consistent with this direct hazard curve. The ground motions selected using $T^{*}=2.6 \mathrm{~s}$ have a stepped plot in Figure $4(\mathrm{c})$, because of the 10 discrete $\mathrm{Sa}(2.6 \mathrm{~s})$ amplitudes that were considered when selecting motions and the fact that $P\left(\mathrm{Sa}(T)>y \mid \mathrm{Sa}\left(T^{*}\right)=x\right)$, when $T=T^{*}$, is equal to either 0 when $y<x$ or 1 when $y>x$. The ground motions with other $T^{*}$ values have smoother curves. All of the curves are in good general agreement, indicating that even though the other sets of ground motions did not scale ground motions to match $\mathrm{Sa}(2.6 \mathrm{~s})$, they have the proper distribution of $\mathrm{Sa}(2.6 \mathrm{~s})$ as specified by the hazard curve at that period. A similar plot is shown in Figure $\underline{4}(\mathrm{~d})$ for the rate of exceeding $\mathrm{Sa}(5 \mathrm{~s})$; in this case, the ground motions with $T^{*}=5 \mathrm{~s}$ have the stepped curve, and the other $T^{*}$ cases are smooth. Again, the curves are in relatively good agreement with the true ground motion hazard curve, except for the case of $T^{*}=0.45 \mathrm{~s}$ at high amplitudes.

As seen from Figure $\underline{4}(\mathrm{c})$ and $(\mathrm{d})$, ground motions selected using the conditioning period, $T^{*}=0.85 \mathrm{~s}$, seem to be rather consistent with the direct hazard curves at 2.6 and $5 \mathrm{~s}$. It is important to ensure that 
response spectra of the selected ground motions match well with the target seismic hazard at the periods that are important to the structural response of interest. If the goal of the analysis is to assess PSDR or collapse, then ground motion hazard consistency at the longer periods (2.6 and $5 \mathrm{~s}$ ) may suffice if higher-mode responses do not contribute significantly to that response parameter. However, if the goal of the analysis involves structural responses that are sensitive to shorter periods (e.g., PFA), then ground motion hazard consistency needs to be enforced at the shorter periods as well. Let us revisit the $T^{*}=0.85 \mathrm{~s}$ case in the shorter period range in addition to the known good match in the longer period range. Spectra of ground motions selected using $T^{*}=0.85 \mathrm{~s}$ from Figure $4(\mathrm{~b})$ are plotted with reference to four periods $(0.45,0.85,2.6$, and $5 \mathrm{~s})$. The corresponding ground motion spectra distributions at these periods are plotted in Figure $\underline{4}(\mathrm{e})$. The dotted lines show the direct hazard curves, whereas the solid lines show the implied hazard curves from the selected ground motions. Note the stepped curve for the ground motions at $0.85 \mathrm{~s}$, due to the 10 discrete $\mathrm{Sa}(0.85 \mathrm{~s})$ amplitudes that were considered when selecting these motions. Figure 4 (e) shows that ground motions selected using $T^{*}=0.85 \mathrm{~s}$ resulted in response spectra that are relatively consistent with known seismic hazard information at all four periods of consideration $(0.45,0.85,2.6$, and $5 \mathrm{~s})$. This set of ground motions using $T^{*}=0.85 \mathrm{~s}$ can thus perhaps be used to evaluate any structural responses, regardless of their corresponding periods of importance.

\subsection{Comparison of approximate and exact conditional spectra}

The quality of the match in response spectra between the selected ground motions and the target seismic hazard curve is good in some cases (e.g., $T^{*}=0.85 \mathrm{~s}$ ) but not others (e.g., $T^{*}=0.45 \mathrm{~s}$ ). The match quality would depend on (i) the accuracy of the computed target spectrum and (ii) the consistency in the distribution between the selected ground motions and the target spectrum. Because the distribution of the selected ground motions matches well with the target spectrum, the major factor would then be the accuracy of the computed target spectrum, where multiple causal earthquakes and GMPMs would be important. When multiple magnitudes and distances (instead of a single earthquake scenario) associated with a given

Earthquake Engineering \& Structural Dynamics, Vol. 42, No. 12 (October 10, 2013): pg. 1847-1865. DOI. This article is (C) Wiley and permission has been granted for this version to appear in e-Publications@Marquette. Wiley does not grant permission for this article to be further copied/distributed or hosted elsewhere without the express permission from Wiley. 
deaggregation are taken into consideration, the variability of the spectrum at periods other than $T^{*}$ is increased relative to the approximate case using only a single mean magnitude and distance. A similar increase in variability also results from making predictions using multiple GMPMs (consistent with the use of multiple models in the hazard calculations) rather than just a single model []].

The increased variability from these factors can be captured formally in the conditional standard deviation computation. The mean $\mathrm{CS}$ is in principle affected by this approximation, but this does not appear to be as significant of a practical issue in many cases. Figure $\underline{5}$ shows approximate and exact CS results for the example site considered here, at short and long conditioning periods []]. Those results indicate that, for this particular site, the approximations that we are using here are very accurate for the 1-s conditioning period but that conditional standard deviations are underestimated by the approximation for the 0.2 -s conditioning period case. The accurate approximation for the 1 -s conditioning period (Figure $\underline{5}(b)$ ) explains why the response spectra of the selected ground motions using $T^{*}=0.85 \mathrm{~s}$ match the seismic hazard well at various periods (Figure $4(\mathrm{e})$ ). As the underestimation of conditional standard deviation is most prominent at periods far from the conditioning period (as seen prominently in Figure $\underline{5}(a)$ and more generally in []]), it is perhaps not surprising that the conditional standard deviations at $\mathrm{Sa}(5 \mathrm{~s})$ for the $T^{*}=0.45 \mathrm{~s}$ case are underestimated, resulting in a lack of highamplitude $\mathrm{Sa}(5 \mathrm{~s})$ values in those ground motions (Figure $\underline{4}(\mathrm{~d})$ ). It is illustrated here that approximate CS may work well for some cases but not others. Ideally, we would use the exact CS calculations for all results presented in this paper, but those calculations are currently rather cumbersome for practical applications (although automated tools for such calculations are envisioned in the near future and an alternative approach is developed by Bradley [26]).

Earthquake Engineering \& Structural Dynamics, Vol. 42, No. 12 (October 10, 2013): pg. 1847-1865. DOI. This article is (C) Wiley and permission has been granted for this version to appear in e-Publications@Marquette. Wiley does not grant permission for this article to be further copied/distributed or hosted elsewhere without the express permission from Wiley. 
NOT THE PUBLISHED VERSION; this is the author's final, peer-reviewed manuscript. The published version may be accessed by following the link in the citation at the bottom of the page.

\subsection{Response spectra refinement}

Given our current limitations with regard to computing exact CS, we approximately correct for the difference between the approximate and exact standard deviations (see, for example, in Figure $\underline{5}(a)$ ) by inflating the approximate standard deviations by some constant. The value of that constant is determined by comparing the Sa distributions from the resulting selected ground motions to the numerical hazard curves at a range of periods. With an appropriate conditional standard deviation, the ground motions should match the corresponding target hazard curves as described. No adjustment is made to the approximate mean spectra, as experience shows them to be similar to exact mean spectra in most cases []].

In the aforementioned results, the ground motions selected using $T^{*}=0.85,2.6$, and $5 \mathrm{~s}$ already showed good agreement with corresponding ground motion hazard curves at 2.6 and $5 \mathrm{~s}$ (Figures $\underline{4}(\mathrm{c})$ and (d)), so no adjustments were made in those cases. For the case of $T^{*}=0.45 \mathrm{~s}$, the conditional standard deviations were inflated by $10 \%$, and ground motions were reselected to match this new target. The spectra of the selected ground motions with $T^{*}=0.45 \mathrm{~s}$ are plotted at four periods versus the corresponding ground motion hazard curves in Figure $\underline{6}$. The spectra from the original ground motions are shown in Figure $\underline{6}(a)$, and the new motions with a $10 \%$ larger standard deviation are shown in Figure $\underline{6}(\mathrm{~b})$.

Note again the stepped curve for the ground motions at $0.45 \mathrm{~s}$, due to the 10 discrete $\mathrm{Sa}(0.45 \mathrm{~s})$ amplitudes that were considered when selecting these motions. The curves in Figure $\underline{6}(\mathrm{a})$ are in relatively good agreement with the true ground motion hazard curve, except for the case of $\mathrm{Sa}(5 \mathrm{~s})$ at high amplitudes and $\mathrm{Sa}(2.6 \mathrm{~s})$ to a lesser extent. With a conditional standard deviation inflated by $10 \%$ for the Figure $\underline{6}$ (b) motions, the curves at 5 and $2.6 \mathrm{~s}$ are in better agreements, demonstrating improved consistency with the known hazard information.

Earthquake Engineering \& Structural Dynamics, Vol. 42, No. 12 (October 10, 2013): pg. 1847-1865. DOI. This article is (C) Wiley and permission has been granted for this version to appear in e-Publications@Marquette. Wiley does not grant permission for this article to be further copied/distributed or hosted elsewhere without the express permission from Wiley. 


\section{Structural Analysis}

For each of the sets of ground motions selected at various intensity levels and conditioning periods, nonlinear dynamic analysis was performed to obtain structural response. The structure considered is a 20-story reinforced concrete perimeter frame. The stiffness and strength degradation were modeled using a lumped plasticity model originally developed by Ibarra et al. [27], with model parameters calibrated from a database of experimental tests of concrete components [15]. This component model includes within-cycle deterioration (i.e., a negative-sloped force-displacement regime) that is necessary to capture behavior of the system up to collapse. Collapses were modeled directly and assumed to have occurred when the frame reached dynamic instability and produced extremely large displacements. No uncertainties in model parameters were considered. P-delta effects were included by considering gravity loads on both the seismic resisting frame and a leaning column.

The objective of nonlinear dynamic analysis here is risk-based assessment, which considers full distribution of structural response at multiple intensity levels along with their occurrence rates. To illustrate, we perform such a computation for PSDR (i.e., maximum SDR observed over all stories, over the duration of shaking). The structural analysis procedure will be presented for a single conditioning period followed by additional conditioning periods, first for ground motion selected to match the approximate CS and next for ground motions with response spectra refinement to ensure hazard consistency.

\subsection{Risk-based assessment procedure}

The risk-based assessment procedure estimates the mean annual rate of structural response amplitude $>y$. It is obtained by integrating the probability of observing a structural response amplitude given a ground motion intensity level $=x$ with the rate of observing those ground motion intensities. The mean annual rate of EDP exceeding $y, \lambda($ EDP $>y)$, can be calculated as follows [2]]:

$$
\lambda(\mathrm{EDP}>y)=\int_{x} P\left(\operatorname{EDP}>y \mid \operatorname{Sa}\left(T^{*}\right)=x\right) \mid \lambda\left(\mathrm{dSa}\left(T^{*}\right)>x \mid\right.
$$

Earthquake Engineering \& Structural Dynamics, Vol. 42, No. 12 (October 10, 2013): pg. 1847-1865. DOI. This article is (C) Wiley and permission has been granted for this version to appear in e-Publications@Marquette. Wiley does not grant permission for this article to be further copied/distributed or hosted elsewhere without the express permission from Wiley. 
where $\lambda\left(\mathrm{dSa}\left(T^{*}\right)>x\right)$ is the derivative of the hazard curve for $\mathrm{Sa}\left(T^{*}\right)$ multiplied by an increment of $\mathrm{dSa}\left(T^{*}\right)$ and $P\left(\operatorname{EDP}>y \mid \mathrm{Sa}\left(T^{*}\right)=x\right)$ is the probability of EDP exceeding $y$ given a ground motion with Sa $\left(T^{*}\right)=x$. For instance, if the EDP of interest is PSDR, $P\left(E D P>y \mid \mathrm{Sa}\left(T^{*}\right)=x\right)$, which is an input to Equation (5), would be $P\left(\operatorname{PSDR}>y \mid \mathrm{Sa}\left(T^{*}\right)=x\right)$, and the resulting risk-based assessment of PSDR, $\lambda($ PSDR $>y)$, can be termed drift hazard. The probability of PSDR exceeding $y$ given a ground motion with Sa $\left(T^{*}\right)=x$ ) can be computed [28]:

$P\left(\operatorname{PSDR}>y \mid \operatorname{Sa}\left(T^{*}\right)=x\right)=P(C)+(1-P(C))\left(1-\Phi\left(\frac{\ln y-\mu_{l n \mathrm{PSDR}}}{\sigma_{\ln \mathrm{PSDR}}}\right)\right)$

where $P(C)$ is the probability of collapse given Sa $\left(T^{*}\right)=x$ estimated from the collapse fragility function, and $\mu_{\text {InPSDR }}$ and $\sigma_{\text {InPSDR }}$ are the mean and standard deviation, respectively, of InPSDR values given Sa $\left(T^{*}\right)=x$ and no collapse. One assumption here is that all collapse cases cause PSDR $>y$.

To illustrate, consider the nonlinear dynamic analysis results of PSDR given Sa (2.6 s) for 10 intensity levels. As illustrated in Figure $\underline{7}(\mathrm{a})$, each 'stripe' of nonlinear dynamic analysis results corresponds to PSDR at one intensity level with its associated Sa (2.6 s) value. As the occurrence rate decreases (or return period increases), the associated Sa (2.6s) value increases, resulting generally in higher structural response (except when a change in deformation mechanism of the system leads to a reduction in a particular response parameter, e.g., structural resurrection as presented in [29]). Structural response at each given ground motion intensity level is assumed to be lognormally distributed e.g., [28, 3034]. Because 40 ground motions are used for each intensity level, the uncertainty in the point-estimated distribution parameters (i.e., logarithmic mean and standard deviation) of structural response given intensity level is relatively small and therefore not explicitly considered. If a structural response threshold is specified (e.g., a PSDR of 0.01 ), probabilities of structural response greater than the threshold value can be obtained as shaded in Figure $\underline{7}(a)$. The observed fractions of collapse can also be plotted for each intensity level, as shown in Figure $\underline{7}$ (b). A fragility function utilizing maximum likelihood e.g., $[\underline{31,35,36]}$ is used to fit the empirical collapse data. 
The PSDR distribution and collapse fragility from Figures $\underline{7}(\mathrm{a})$ and (b) can be combined with the corresponding seismic hazard curve from Figure $1(a)$, to estimate the mean annual rate of PSDR $>y$ in Figure $\underline{7}(\mathrm{c})$ ) for $T^{*}=2.6 \mathrm{~s}$ by using Equation (5) (through Equation (6)).

\subsection{Varying conditioning periods}

To evaluate the impact of conditioning period on risk-based assessment, we can perform structural analyses by using ground motions selected to match the CS at various conditioning periods. Calculations similar to those for $T^{*}=2.6 \mathrm{~s}$ were repeated for the other three periods: $T^{*}=0.45 \mathrm{~s}, T^{*}=0.85 \mathrm{~s}$, and $T^{*}=5 \mathrm{~s}$. Collapse fragility functions obtained from the four sets of structural analyses are shown in Figure $\underline{7}$ (b) and risk-based assessments of PSDR in Figure $\underline{7}$ (c) by using the approximate CS.

The impact of the conditioning period $T^{*}$ on structural response can be assessed on the basis of the structural analysis objective. If the objective is an intensity-based assessment, as illustrated in Figure $\underline{7}$ (b) for predicted collapse fragilities, then the conditioning period would have a major impact. However, if the objective is a risk-based assessment, as illustrated in Figure $\underline{7}(\mathrm{c})$, that takes into account, not only the structural response at any given intensity level but also the occurrence frequency of the ground motions used to assess those structural response, then the results would be relatively insensitive to the choice of conditioning period. The difference between Figures $\underline{7}$ (b) and $(c)$ is the integration with ground motion hazard occurrence (absent in Figure $\underline{7}$ (b) but present in Figure $\underline{7}(\mathrm{c})$ ). Risk-based assessments of PSDR show fairly good agreements by using the approximate CS at four conditioning periods except for $0.45 \mathrm{~s}$, which will be covered in the next section by using the refined CS.

\subsection{Significance of hazard consistency}

Let us now look at what difference hazard-consistent refinement of target spectra would make on structural response. Recall that conditional standard deviation was inflated for $0.45 \mathrm{~s}$ to approximately correct for the difference between the approximate and exact CS, so 
that the Sa distribution from the selected response spectra matches better with the target ground motion hazard curve.

The resulting collapse fragility functions are shown in Figure $\underline{8}(a)$. The inflated conditional standard deviation resolves the deficiency in high-amplitude Sa values especially for long periods (Figure $\underline{6}(\mathrm{~b})$ vs. $\underline{6}(\mathrm{a})$ ), which are important for collapse, and therefore results in a higher probability of collapse for a given $\mathrm{Sa}(0.45 \mathrm{~s})$ amplitude.

Another potential reason that the 0.45 -s case did not work well compared with the other three conditioning periods (Figure $\underline{7}(\mathrm{c})$ ) is that the collapse fragility curve was not well constrained because of a lower fraction of observed collapses (only $40 \%$ even for the highest Sa amplitudes, as illustrated in Figure $\underline{7 b}$ ). To test the sensitivity of the collapse results to the absence of higher-amplitude Sa levels, we performed additional ground motion selection and structural analyses for the 0.45 -s case at higher Sa amplitudes but found that the collapse fragility curves did not change much with more constraints from collapse observations at additional higher-amplitude Sa levels documented in Appendix A of [37]. There are cases, however, when a poorly constrained collapse fragility curve may distort the result significantly, for example, with the highest observed probability of collapse of less than $10 \%$, as seen in some of the structures and period combinations in calculations of this type documented in Appendix A of [37].

The risk-based assessment of PSDR was recomputed using these new motions with adjusted conditional standard deviation and is compared with the original result for $T^{*}=0.45 \mathrm{~s}$ in Figure $\underline{8}(\mathrm{~b})$. The horizontal portion of the PSDR risk-based assessment curve is dominated by collapse for higher PSDR, so the higher probability of collapse with the inflated conditional standard deviation would result in a higher annual rate of exceeding PSDR as well. The new risk-based assessment result is also compared with the previous risk-based assessment results by using other conditional periods in Figure $\underline{9}$, and the agreement among these four curves is very good. This suggests that if we carefully select ground motions with appropriate conditional standard deviations to match the true hazard curves, risk-based

Earthquake Engineering \& Structural Dynamics, Vol. 42, No. 12 (October 10, 2013): pg. 1847-1865. DOI. This article is (C) Wiley and permission has been granted for this version to appear in e-Publications@Marquette. Wiley does not grant permission for this article to be further copied/distributed or hosted elsewhere without the express permission from Wiley. 
assessments would be in good agreements regardless of the choice of conditioning periods.

Despite this refinement, we have still only considered spectral values here and not other ground motion properties that in some cases may be relevant to structural response (e.g., velocity pulses and duration). If non-spectral ground motion parameters are also deemed important for predicting the EDP of interest, the approach presented earlier can be generalized to account for those parameters and quantify the correlations between additional parameters of interest, as recently developed by Bradley [10].

\section{Additional Engineering Demand Parameters}

Risk-based assessment of PSDR has been presented in the earlier sections. Story drift is often used in structural analysis as it is highly correlated with structural damage e.g., [38]. However, depending on the focus of the structural analysis, the structural response parameter of interest may vary. To help illustrate the generality of the aforementioned results, we now consider PFA (i.e., maximum acceleration observed over all floors including the ground, over the duration of shaking) as well as SDR (i.e., maximum story drift ratio observed at a single story, over the duration of shaking) and floor acceleration (FA, i.e., maximum acceleration observed at a single floor, over the duration of shaking). PFAs are often observed at upper stories of the example building and are sensitive to excitation of higher modes of the building, so they are not highly correlated with PSDRs (which are more closely related to first-mode response). Hazard consistency of ground motions should again be ensured at the periods of interest, that is, at shorter periods (high-mode periods) for PFAs.

Some adjustments of conditional standard deviations were again needed to ensure hazard consistency of the short-period Sa when the conditioning period was first mode or longer (because these shortperiod spectra are important for PFA). Figure 10 compares the Sa distributions from the ground motions selected with $T^{*}=2.6 \mathrm{~s}$ (Figure $\underline{10}(\mathrm{a})$ and (b)) and $T^{*}=5 \mathrm{~s}$ (Figure $\underline{10}(\mathrm{c})$ and (d)), to the numerical hazard curves at a range of periods $(0.45,0.85,2.6$, and $5 \mathrm{~s}$ ), without (Figure $\underline{10}(\mathrm{a})$ and (c)) and with (Figure $\underline{10}(\mathrm{~b})$ and (d)) conditional standard deviation adjustments. Approximate CSs (with a

Earthquake Engineering \& Structural Dynamics, Vol. 42, No. 12 (October 10, 2013): pg. 1847-1865. DOI. This article is (C) Wiley and permission has been granted for this version to appear in e-Publications@Marquette. Wiley does not grant permission for this article to be further copied/distributed or hosted elsewhere without the express permission from Wiley. 
single causal earthquake $M / R / \epsilon$ and a single GMPM) were used in Figure $\underline{10}(\mathrm{a})$ and (c) for $T^{*}=2.6 \mathrm{~s}$ and $T^{*}=5 \mathrm{~s}$, respectively. Note again the stepped curve for the ground motions at $2.6 \mathrm{~s}$ (Figure $\underline{10}(\mathrm{a})$ ) and $5 \mathrm{~s}$ (Figure $\underline{10}(\mathrm{c})$ ), due to the 10 discrete $\mathrm{Sa}\left(T^{*}\right)$ amplitudes that were considered when selecting these motions. The curves in Figure $\underline{10}(\mathrm{a})$ and (c) using the selected ground motions match well with the true ground motion hazard curve at longer periods ( 2.6 and $5 \mathrm{~s}$ ) but not as well at shorter periods (especially $0.45 \mathrm{~s}$ ), which are important for PFA. By comparing the Sa distributions from the resulting selected ground motions (by using approximate conditional standard deviation) to the true hazard curves, we approximately correct for the difference between the approximate and exact standard deviations by inflating the approximate standard deviations by some constant. For the case of $T^{*}=2.6 \mathrm{~s}$ and $T^{*}=5 \mathrm{~s}$, the conditional standard deviations were inflated by $30 \%$, and ground motions were reselected to match this new target. With a conditional standard deviation inflated by $30 \%$ for the Figure 10 (b) and (d) motions, the curves at $0.45 \mathrm{~s}$ are in better agreements, demonstrating improved consistency with the known hazard information.

The risk-based assessment procedure is similar to those for PSDR hazard calculations except the following: for PFA, collapse PFA is assumed to be the peak ground acceleration (PGA) for the corresponding ground motion because PFAs are close to PGA when the building experiences strong nonlinear behavior (except for collapse mechanisms that cause partial collapse in the upper floors) [33]. Hence, the logarithmic mean and standard deviation of PFA, $\mu_{\ln \text { PFA }}$ and $\sigma_{\text {InPFA, }}$ can be evaluated directly including both collapse and noncollapse cases, slightly different from the PSDR evaluations. The probability of PFA exceeding $y$ given a ground motion with $\mathrm{Sa}\left(T^{*}\right)=x$, $P\left(\mathrm{PFA}>y \mid \mathrm{Sa}\left(T^{*}\right)=x\right)$, can then be easily computed as

$$
P\left(\mathrm{PFA}>y \mid \mathrm{Sa}\left(T^{*}\right)=x\right)=1-\Phi\left(\frac{\ln y-\mu_{\ln \mathrm{PFA}}}{\sigma_{\ln \mathrm{PFA}}}\right)_{(7)}
$$

With the computed $P\left(\operatorname{PFA}>y \mid \mathrm{Sa}\left(T^{*}\right)=x\right)$, the mean annual rate of PFAs exceeding $y, \lambda($ PFA $>y)$ can be calculated according to Equation (5) where the EDP of interest is PFA.

Earthquake Engineering \& Structural Dynamics, Vol. 42, No. 12 (October 10, 2013): pg. 1847-1865. DOI. This article is (C) Wiley and permission has been granted for this version to appear in e-Publications@Marquette. Wiley does not grant permission for this article to be further copied/distributed or hosted elsewhere without the express permission from Wiley. 
NOT THE PUBLISHED VERSION; this is the author's final, peer-reviewed manuscript. The published version may be accessed by following the link in the citation at the bottom of the page.

Figure 11(a) shows the PFA risk-based assessment curves obtained with four choices of $T^{*}$ by using an approximate conditional standard deviation, whereas Figure $\underline{11}$ (b) shows these curves by using an inflated conditional standard deviation for the cases of $\mathrm{Sa}(2.6 \mathrm{~s})$ and $\mathrm{Sa}(5 \mathrm{~s})$. Once appropriate conditional standard deviations were determined for each conditioning period, the risk-based assessment results are more consistent, as illustrated through the improvements from Figure 11(a) to (b). This again shows the importance of hazard consistency on risk-based assessment results, and that once such hazard consistency is ensured, risk-based assessment results are relatively insensitive to the choice of conditioning period.

The results of Figures $\underline{9}$ and $\underline{11}$ (b) are also presented in Table $\underline{1}$, to illustrate ( $i$ ) the differences in the values of exceedance rate for a given EDP value by using different conditional periods (in the top portion of the table); and (ii) the differences in EDP for a given exceedance rate by using different conditional periods (in the bottom portion of the table). Annual rates of PSDR $>2 \%$, annual rates of PFA $>0.5 \mathrm{~g}$, and annual rates of collapse as well as median PSDR and median PFA corresponding to $10 \%$ in 50-year exceedance rates are shown for all four conditioning periods $\left(T^{*}=0.45,0.85,2.6\right.$, and $5 \mathrm{~s}$ ) considered here. The values (i) are in the range of $6.46 \times 10^{-4}$ to $9.42 \times 10^{-4}$ for annual rates of PSDR $>2 \%, 2.12 \times 10^{-3}$ to $2.56 \times 10^{-3}$ for annual rates of PFA $>0.5 \mathrm{~g}$, and $3.12 \times 10^{-4}$ to $5.02 \times 10^{-4}$ for annual rates of collapse. The values (ii) are between 0.011 and 0.012 for median PSDR, corresponding to $10 \%$ in 50 -year exceedance rates, and between 0.500 and 0.529 for median PFA, corresponding to $10 \%$ in 50-year exceedance rates. These differences are considered small for the range of conditioning periods investigated.

Similar results are shown in Figure 12 for SDR and FAs observed on the 15 th story of the structure (rather than the maximum response across all stories). These parameters are used to illustrate the prediction of single-story response parameters that are often of interest in loss assessment calculations. Figure 12 illustrates that these predictions are also consistent when differing conditioning periods are considered.

Earthquake Engineering \& Structural Dynamics, Vol. 42, No. 12 (October 10, 2013): pg. 1847-1865. DOI. This article is (C) Wiley and permission has been granted for this version to appear in e-Publications@Marquette. Wiley does not grant permission for this article to be further copied/distributed or hosted elsewhere without the express permission from Wiley. 
The results in this section again demonstrate the consistency of risk-based assessments across conditioning periods. They also indicate the importance of ensuring hazard consistency of the response spectra at periods related to the structural response parameter of interest (or more generally, hazard consistency of any ground motion intensity measure of interest). If an approximate CS is used as the target response spectrum, EDP-specific adjustments in conditional standard deviation may be needed to achieve better hazard consistency. This is because different EDPs are correlated with spectral amplitudes at different periods, and capturing the variability of spectra at periods (especially those associated with the EDPs of interest) away from the conditioning period is important. Although hazard consistency was improved for periods and Sa amplitudes of most interest given an EDP, uniformly inflating the conditional standard deviation of the target spectra (as was performed in the approximate refinement cases) may result in overestimations or underestimations at other periods or Sa amplitudes, because conditional standard deviations do not scale uniformly. Alternatively, if the exact CS is used as the target response spectrum, the same input ground motions can be used for structural analysis to obtain all EDPs of interest-this would be the most robust method for performance-based earthquake engineering that is interested in performance quantities, which require characterization of the uncertainty in EDP estimates, given ground motion intensity levels, for example, loss estimation (as a result of damage to drift-sensitive and acceleration-sensitive components). The exact CS does not require EDPs to be known prior to ground motion selection; in other words, the EDP-specific spectra refinement to ensure hazard consistency is not needed for the exact CS.

Through this study, it is shown that the target response spectrum is just an intensity measure that connects the seismic hazard and structural response. If this connection is maintained carefully, for example, through the CS, then structural response results should be consistent. In fact, 11 additional structures were analyzed in Appendix A of [37]. Despite the different conditioning periods adopted in each structure, there was internally consistent agreement in risk-based structural response results for each structure, but the risk-based structural response results differed from structure to structure.

Earthquake Engineering \& Structural Dynamics, Vol. 42, No. 12 (October 10, 2013): pg. 1847-1865. DOI. This article is (C) Wiley and permission has been granted for this version to appear in e-Publications@Marquette. Wiley does not grant permission for this article to be further copied/distributed or hosted elsewhere without the express permission from Wiley. 
NOT THE PUBLISHED VERSION; this is the author's final, peer-reviewed manuscript. The published version may be accessed by following the link in the citation at the bottom of the page.

\section{Conclusions}

This paper has presented a study on the sensitivity of risk-based assessment (in the context of EDP hazard) results to the choice of conditioning period when using the CS as the target for ground motion selection and scaling. The study focused on risk-based assessments, with a specific emphasis on the rates of exceeding various levels of PSDR (i.e., drift hazard calculations) in the structure. Some additional EDPs were also considered, such as the PFA over the full building heights, a single-story SDR, and a single-story FA. The structure considered was a 20-story reinforced concrete frame structure assumed to be located in Palo Alto, California, using a structural model with strength and stiffness deterioration that is believed to reasonably capture the responses up to the point of collapse due to dynamic instability.

The risk-based assessments were performed on the basis of ground motions selected and scaled to match the CS, where four conditioning periods, $0.45,0.85,2.6$, and $5 \mathrm{~s}$ were used (i.e., the building's third-mode structural period up to approximately twice the first-mode period). These conditioning periods were chosen to illustrate how the assessment results varied across a wider range of periods, rather than because there is something special about these specific periods. For each case, the risk-based assessment results were found to be similar. The similarity of the results stems from the fact that the careful record selection ensures that the distributions of response spectra at all periods are nominally comparable, so the distribution of resulting structural responses should also be comparable (to the extent that response spectra describe the relationship between the ground motions and structural responses).

From these results, it is observed that if the analysis goal is to perform a risk-based assessment, then one should be able to obtain an accurate result by using any conditioning period, provided that the ground motions are selected carefully to ensure proper representation of spectral values and other ground motion parameters of interest. Here, 'proper representation' refers to consistency with the site ground motion hazard curves at all relevant periods, and this is achieved by using the CS approach to determine target response spectra for the 
selected ground motions. The reproducibility of the risk-based assessment results, for varying conditioning periods, then results from the fact that the ground motion intensity measure used to link the ground motion hazard and the structural response is not an inherent physical part of the seismic reliability problem considered; it is only a useful link to decouple the hazard and structural analysis. If this link is maintained carefully, then one should obtain a consistent prediction (the correct answer) of the risk-based assessment in every case. The consistency in risk-based assessment that is demonstrated here is in contrast to some previous speculation on this topic, because this study utilizes the recently developed CS for ground motion selection, and uses the first available algorithm for selecting ground motions to match this CS target (which includes both mean and variability in the target spectra).

One practical challenge associated with these findings is that selecting ground motions that are truly consistent with ground motion hazard at all periods requires the use of an exact target CS (i.e., one that accounts for multiple causal magnitudes and distances associated with a given Sa amplitude, and for multiple GMPMs); practical computation of this CS target, however, typically considers only a single GMPM and only the mean magnitude and distance from deaggregation. The computation of the exact CS target is more difficult in practice. Here, the approximate CS is used, and its conditional standard deviation is adjusted to achieve consistency of the selected ground motion spectra with corresponding ground motion hazard, at the periods important to the problem being studied. This adjustment is not needed in most cases, but in some cases, it is necessary and greatly improves the robustness of the risk-based assessment results. In the future, exact CS targets can be more readily developed, and this adjustment will not be necessary.

This paper has shown that the results of a risk-based assessment are relatively insensitive to conditioning period, $T^{*}$, provided that ground motions have been carefully selected using the conditional spectrum-based selection process. The natural question is: Is the choice of conditioning period still important at all? Yes; the choice of a good conditioning period does still serve several useful purposes. Selecting a good conditioning period helps because the Sa at the conditioning period will be a good predictor of structural response; 
this leads to any inaccuracies in representing spectral values at other periods having a less severe impact on the resulting risk-based assessment predictions. Additionally, the use of a good conditioning period reduces the variability in structural responses (effects of intensity measure selection on structural response prediction and loss estimation are also investigated by Bradley et al. $[\underline{39,40])}$ and thus reduces the number of nonlinear dynamic analyses that is required to accurately estimate distributions of EDP. Luco et al. [41] referred to these two properties as 'sufficiency' and 'efficiency', respectively. Those concepts are taken further in this study, acknowledging that there is no intensity measure with perfect efficiency and sufficiency, and so careful ground motion selection is performed to compensate for shortcomings that are inherent in any intensity measure. Bradley [11] provides consistent and complementary results to those presented in this manuscript on the basis of the use of the generalized conditional intensity measure.

\section{Acknowledgements}

The authors thank Brendon Bradley, Eduardo Miranda, Gregory Deierlein, and an anonymous reviewer for their helpful reviews of the manuscript. The authors also acknowledge the contributions of Jared DeBock and Fortunato Enriquez in conducting the structural analyses used in this study. This work was part of a larger project on ground motion selection [42]. It was supported in part by the NEHRP Consultants Joint Venture (a partnership of the Consortium of Universities for Research in Earthquake Engineering and Applied Technology Council), under Contract SB134107CQ0019, Earthquake Structural and Engineering Research, issued by the National Institute of Standards and Technology, for project ATC-82. Any opinions, findings, and conclusions or recommendations expressed in this material are those of the authors and do not necessarily reflect those of the NEHRP Consultants Joint Venture.

\section{REFERENCES}

1 Cornell CA, Krawinkler H.Progress and challenges in seismic performance assessment. PEER Center News 2000; 3(2):1-3.

2 Krawinkler H, Miranda E.Performance-based earthquake engineering. In Earthquake Engineering: From Engineering Seismology to Performance-Based Engineering, Bozorgnia Y, Bertero V V (eds.) CRC Press: Boca Raton, 2004.

Earthquake Engineering \& Structural Dynamics, Vol. 42, No. 12 (October 10, 2013): pg. 1847-1865. DOI. This article is (C) Wiley and permission has been granted for this version to appear in e-Publications@Marquette. Wiley does not grant permission for this article to be further copied/distributed or hosted elsewhere without the express permission from Wiley. 
NOT THE PUBLISHED VERSION; this is the author's final, peer-reviewed manuscript. The published version may be accessed by following the link in the citation at the bottom of the page.

3 ATC. Guidelines for seismic performance assessment of buildings, ATC-58 100\% draft. Technical Report, Applied Technology Council, Redwood City, California, 2011.

4 Lin T, Haselton CB, Baker JW.Conditional-spectrum-based ground motion selection. Part II: Intensity-based assessments and evaluation of alternative target spectra. Earthquake Engineering \& Structural Dynamics 2013. DOI 10.1002/eqe.2303.

5 Baker JW, Cornell CA.Spectral shape, epsilon and record selection. Earthquake Engineering \& Structural Dynamics 2006; 35(9):10771095, DOI 10.1002/eqe.571.

6 Baker JW. Conditional mean spectrum: Tool for ground motion selection. Journal of Structural Engineering 2011; 137(3):322-331.

7 Lin T, Harmsen SC, Baker JW, LuCo N.Conditional spectrum computation incorporating multiple causal earthquakes and ground motion prediction models. Bulletin of the Seismological Society of America 2013; 103(2A):1103-1116, DOI 10.1785/0120110293.

8 Jayaram N, Lin T, Baker JW.A computationally efficient ground-motion selection algorithm for matching a target response spectrum mean and variance. Earthquake Spectra 2011; 27(3):797-815, DOI 10.1193/1.3608002.

9 Bradley BA.A generalized conditional intensity measure approach and holistic ground-motion selection. Earthquake Engineering \& Structural Dynamics 2010; 39(12):1321-1342, DOI 10.1002/eqe.995.

10 Bradley BA.A ground motion selection algorithm based on the generalized conditional intensity measure approach. Soil Dynamics and Earthquake Engineering 2012; 40(0):48-61, DOI 10.1016/j.soildyn.2012.04.007.

11 Bradley BA. The seismic demand hazard and importance of the conditioning intensity measure. Earthquake Engineering \& Structural Dynamics 2012; 41(11):1417-1437, DOI 10.1002/eqe.2221.

12 Haselton CB, Baker JW.Ground motion intensity measures for collapse capacity prediction: Choice of optimal spectral period and effect of spectral shape, 8th National Conference on Earthquake Engineering: San Francisco, California, 2006; 10pp.

13 Shome N, Cornell CA, Bazzurro P, Carballo JE.Earthquakes, records, and nonlinear responses. Earthquake Spectra 1998; 14(3):469-500.

14 ATC. Quantification of building seismic performance factors, FEMA P695. Technical Report, Applied Technology Council: Redwood City, California, 2009.

15 Haselton CB, Deierlein GG.Assessing seismic collapse safety of modern reinforced concrete moment frame buildings. Technical Report 2007/08, Pacific Earthquake Engineering Research Center: Berkeley, $C A, 2007$.

Earthquake Engineering \& Structural Dynamics, Vol. 42, No. 12 (October 10, 2013): pg. 1847-1865. DOI. This article is (C) Wiley and permission has been granted for this version to appear in e-Publications@Marquette. Wiley does not grant permission for this article to be further copied/distributed or hosted elsewhere without the express permission from Wiley. 
NOT THE PUBLISHED VERSION; this is the author's final, peer-reviewed manuscript. The published version may be accessed by following the link in the citation at the bottom of the page.

16 OpenSEES. Open system for earthquake engineering simulation. Pacific Earthquake Engineering Research Center, 2011. (Available from: http://opensees.berkeley.edu/ [Accessed on Sep 9, 2011]).

17 ICC. International Building Code 2003, International Code Council: Falls Church, VA, 2003.

18 Boore DM, Atkinson GM.Ground-motion prediction equations for the average horizontal component of PGA, PGV, and 5\%-damped PSA at spectral periods between $0.01 \mathrm{~s}$ and $10.0 \mathrm{~s}$. Earthquake Spectra 2008; 24(1):99-138.

19 Campbell KW, Bozorgnia Y.NGA ground motion model for the geometric mean horizontal component of PGA, PGV, PGD and 5\% damped linear elastic response spectra for periods ranging from 0.01 to $10 \mathrm{~s}$. Earthquake Spectra 2008; 24(1):139-171, DOI 10.1193/1.2857546.

20 Chiou BSJ, Youngs RR.An NGA model for the average horizontal component of peak ground motion and response spectra. Earthquake Spectra 2008; 24(1):173-215, DOI 10.1193/1.2894832.

21 Abrahamson NA, Al Atik L.Scenario spectra for design ground motions and risk calculation, 9th US National and 10th Canadian Conference on Earthquake Engineering: Toronto, Canada, 2010; Paper Number 1896, $12 p p$.

22 Gulerce Z, Abrahamson NA.Site-specific design spectra for vertical ground motion. Earthquake Spectra 2011; 27(4):1023-1047.

23 Baker JW, Jayaram N.Correlation of spectral acceleration values from NGA ground motion models. Earthquake Spectra 2008; 24(1):299-317.

24 Jayaram N, Baker JW.Statistical tests of the joint distribution of spectral acceleration values. Bulletin of the Seismological Society of America 2008; 98(5):2231-2243, DOI 10.1785/0120070208.

25 Chiou B, Darragh R, Gregor N, Silva W.NGA project strong-motion database. Earthquake Spectra 2008; 24(1):23-44, DOI 10.1193/1.2894831.

26 Bradley BA.OpenSHA Implementation of the GCIM Approach for Ground Motion Selection. Southern California Earthquake Center (SCEC) Annual Meeting: Palm Springs, CA, (2010).

27 Ibarra LF, Medina RA, Krawinkler H. Hysteretic models that incorporate strength and stiffness deterioration. Earthquake Engineering \& Structural Dynamics 2005; 34(12):1489-1511.

28 Shome N, Cornell CA.Probabilistic seismic demand analysis of nonlinear structures. Technical Report RMS-35, RMS Program: Stanford, CA, 1999.

29 Vamvatsikos $D$, Cornell CA.Incremental dynamic analysis. Earthquake Engineering \& Structural Dynamics 2002; 31(3):491-514.

Earthquake Engineering \& Structural Dynamics, Vol. 42, No. 12 (October 10, 2013): pg. 1847-1865. DOI. This article is C Wiley and permission has been granted for this version to appear in e-Publications@Marquette. Wiley does not grant permission for this article to be further copied/distributed or hosted elsewhere without the express permission from Wiley. 
NOT THE PUBLISHED VERSION; this is the author's final, peer-reviewed manuscript. The published version may be accessed by following the link in the citation at the bottom of the page.

30 Song J, Ellingwood BR.Seismic reliability of special moment steel frames with welded connections: I. Journal of Structural Engineering 1999; 125(4):357-371.

31 Shinozuka M, Feng MQ, Lee J, Naganuma T.Statistical analysis of fragility curves. Journal of Engineering Mechanics 2000; 126(12):1224-1231.

32 Sasani M, Kiureghian AD.Seismic fragility of RC structural walls: Displacement approach. Journal of Structural Engineering 2001; 127(2):219-228.

33 Aslani H, Miranda E.Probability-based seismic response analysis. Engineering Structures 2005; 27(8):1151-1163.

34 Stoica M, Medina RA, McCuen RH.Improved probabilistic quantification of drift demands for seismic evaluation. Structural Safety 2007; 29(2):132-145.

35 Baker JW.Vector-valued ground motion intensity measures for probabilistic seismic demand analysis. PhD Thesis, Stanford University, 2005.

36 Straub D, Kiureghian AD. Improved seismic fragility modeling from empirical data. Structural Safety 2008; 30(4):320-336.

37 Lin T.Advancement of hazard-consistent ground motion selection methodology. PhD Thesis, Stanford University, 2012.

38 ATC. An Investigation of the Correlation Between Earthquake Ground Motion and Building Performance, ATC-10 Technical Report: Applied Technology Council: Palo Alto, California, 1982.

39 Bradley BA, Dhakal RP, MacRae GA, Cubrinovski M.Prediction of spatially distributed seismic demands in specific structures: Ground motion and structural response. Earthquake Engineering \& Structural Dynamics 2010; 39(5):501-520, DOI 10.1002/eqe.954.

40 Bradley BA, Dhakal RP, MacRae GA, Cubrinovski M.Prediction of spatially distributed seismic demands in specific structures: Structural response to loss estimation. Earthquake Engineering \& Structural Dynamics 2010; 39(6):591-613, DOI 10.1002/eqe.955.

41 Luco N, Cornell CA.Structure-specific scalar intensity measures for nearsource and ordinary earthquake ground motions. Earthquake Spectra 2007; 23(2):357-392.

42 NIST. Selecting and scaling earthquake ground motions for performing response-history analyses, NIST GCR 11-917-15. Technical Report, prepared by the NEHRP Consultants Joint Venture for the National Institute of Standards and Technology, Gaithersburg, Maryland, 2011.

Correspondence to: Ting Lin, Department of Civil and Environmental Engineering, Stanford University, Stanford, CA 94305-4020, USA.

E-mail: tinglin@stanford.edu

Earthquake Engineering \& Structural Dynamics, Vol. 42, No. 12 (October 10, 2013): pg. 1847-1865. DOI. This article is (C) Wiley and permission has been granted for this version to appear in e-Publications@Marquette. Wiley does not grant permission for this article to be further copied/distributed or hosted elsewhere without the express permission from Wiley. 
NOT THE PUBLISHED VERSION; this is the author's final, peer-reviewed manuscript. The published version may be accessed by following the link in the citation at the bottom of the page.

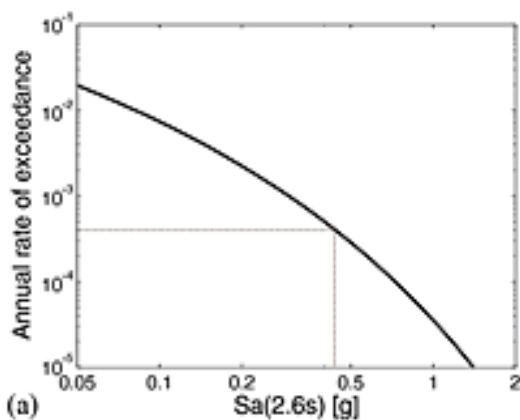

Figure 1.

(a) Seismic hazard curve for $\mathrm{Sa}(2.6 \mathrm{~s})$ and (b) deaggregation at $2 \%$ in 50 -year probability of exceedance.

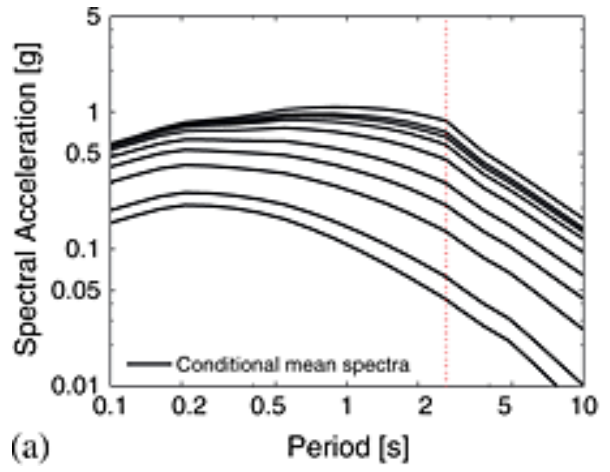

Figure 2.

Target response spectra of (a) CMS at $T^{*}=2.6 \mathrm{~s}$ at multiple intensity levels (from $50 \%$ in 30 years to $1 \%$ in 200 years) and (b) CMS at multiple conditioning periods $(0.45,0.85,2.6$, and $5 \mathrm{~s}$ with UHS superimposed) at the $2 \%$ in 50 -year intensity level.
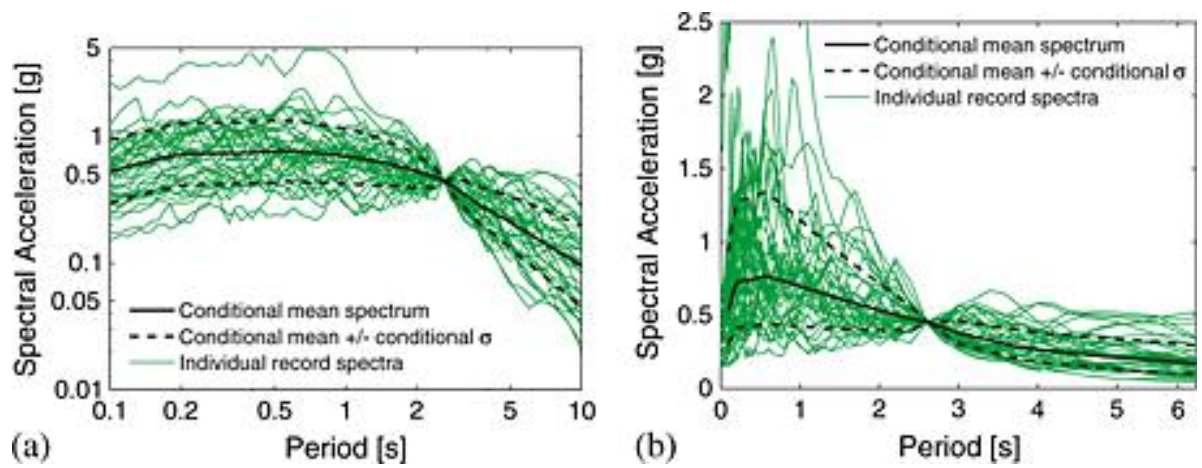

Figure 3.

Response spectra of selected ground motions with CS as target spectra for $\mathrm{Sa}(2.6 \mathrm{~s})$ associated with $2 \%$ in 50 -year probability of exceedance (a) in log scale and (b) in linear scale.

Earthquake Engineering \& Structural Dynamics, Vol. 42, No. 12 (October 10, 2013): pg. 1847-1865. DOI. This article is (C) Wiley and permission has been granted for this version to appear in e-Publications@Marquette. Wiley does not grant permission for this article to be further copied/distributed or hosted elsewhere without the express permission from Wiley. 
NOT THE PUBLISHED VERSION; this is the author's final, peer-reviewed manuscript. The published version may be accessed by following the link in the citation at the bottom of the page.
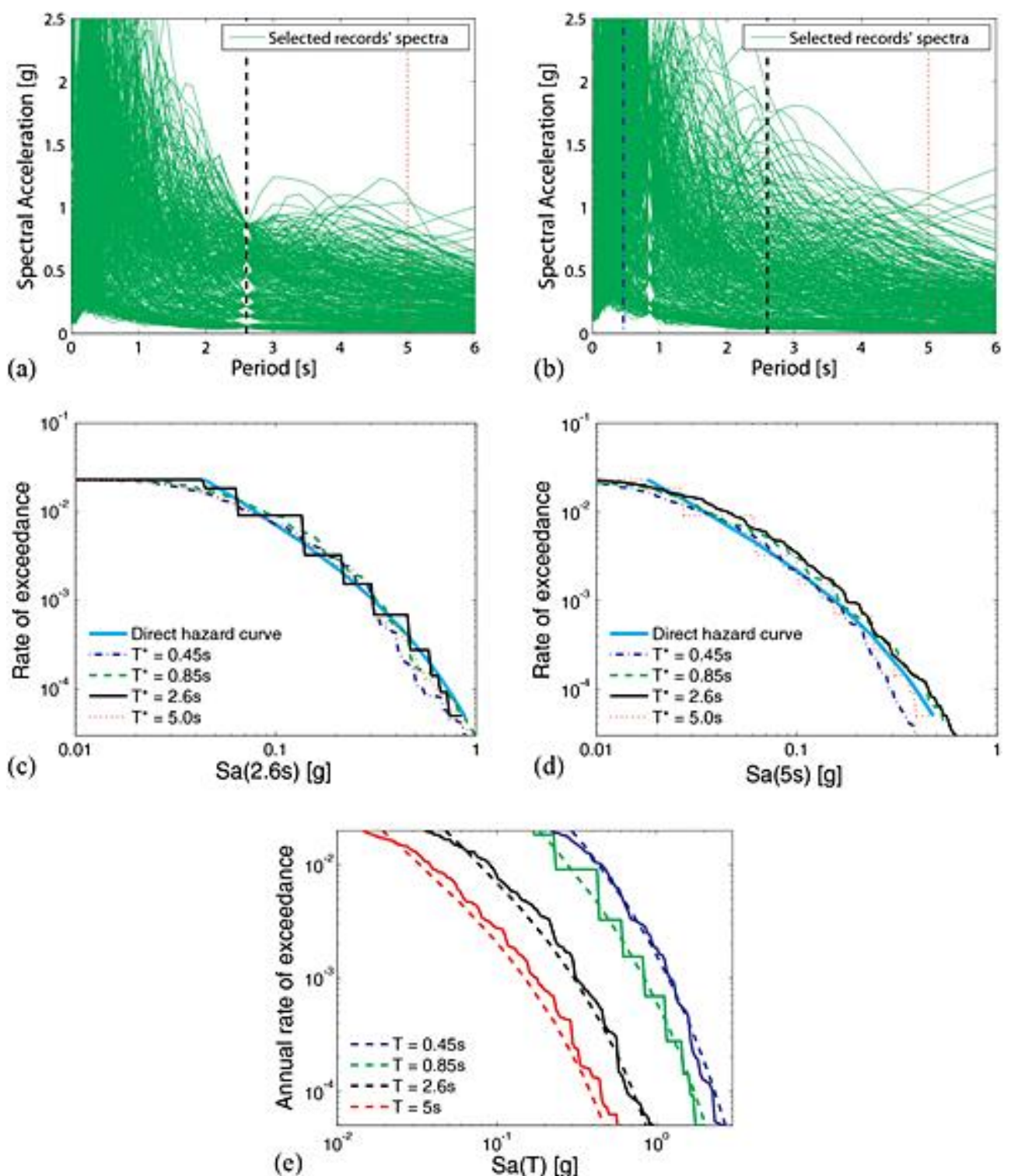

Figure 4.

(a) Ground motion response spectra for ground motions selected at $T^{*}=2.6 \mathrm{~s}$, to match the CS $\mu$ and $\sigma$ (at all intensity levels). (b) Ground motion response spectra for ground motions selected at $T^{*}=0.85 \mathrm{~s}$, to match the CS $\mu$ and $\sigma$ (at all intensity levels). (c) Sa distribution at $\mathrm{Sa}(2.6 \mathrm{~s})$ for ground motions selected at four conditioning periods, $\mathrm{CS} \mu$ and $\sigma$. (d) Sa distribution at $\mathrm{Sa}(5 \mathrm{~s})$ for ground motions selected at four conditioning periods, CS $\mu$ and $\sigma$. (e) Sa distribution at four periods for ground motions selected at $T^{*}=0.85 \mathrm{~s}, \mathrm{CS} \mu$ and $\sigma$.

Earthquake Engineering \& Structural Dynamics, Vol. 42, No. 12 (October 10, 2013): pg. 1847-1865. DOI. This article is (C) Wiley and permission has been granted for this version to appear in e-Publications@Marquette. Wiley does not grant permission for this article to be further copied/distributed or hosted elsewhere without the express permission from Wiley. 
NOT THE PUBLISHED VERSION; this is the author's final, peer-reviewed manuscript. The published version may be accessed by following the link in the citation at the bottom of the page.
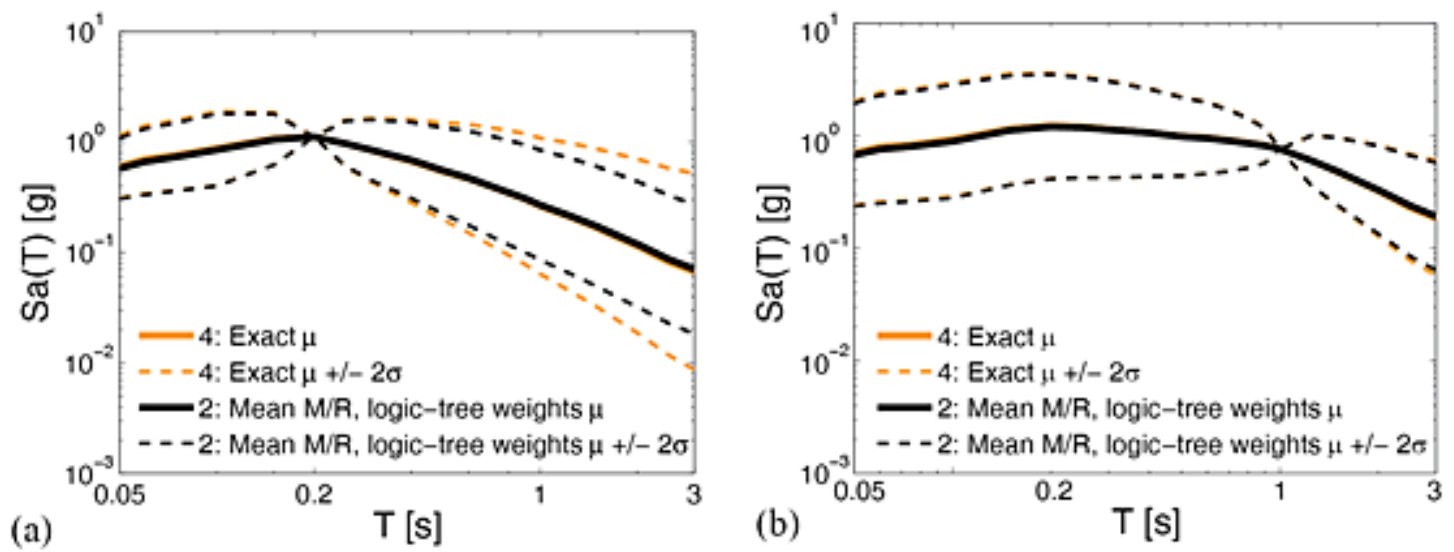

Figure 5.

Exact and approximate $\mathrm{CS}$, given $\mathrm{Sa}\left(T^{*}\right)$ with $2 \%$ probability of exceedance in 50 years. Exact results are denoted '4: Exact', and approximate results are denoted ' 2 : Mean M/R, logic tree weights' in the legend. (a) CS using $T^{*}=0.2 \mathrm{~s}$. (b) CS using $T^{*}=1 \mathrm{~s}$. Results from [ $]$ ]

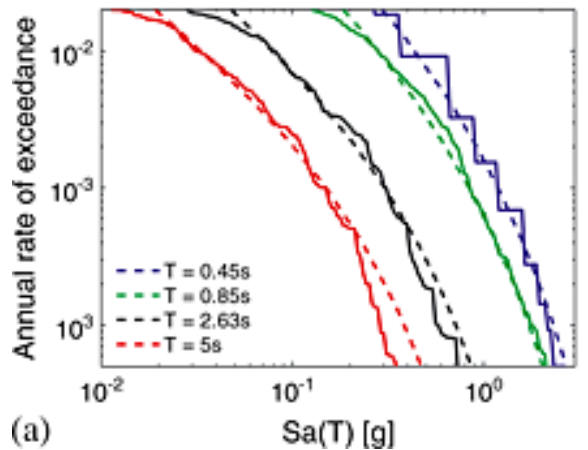

(a)

Figure 6.

Comparisons of selected ground motion spectra at four periods (in solid lines) versus corresponding ground motion hazard curves (in dashed lines). (a) Ground motions selected with $T^{*}=0.45 \mathrm{~s}$ and using basic approximate CS. (b) Ground motions selected with $T^{*}=0.45 \mathrm{~s}$ and by using approximate CS with conditional standard deviations inflated by $10 \%\left(' 1.1 \sigma^{\prime}\right)$.
Earthquake Engineering \& Structural Dynamics, Vol. 42, No. 12 (October 10, 2013): pg. 1847-1865. DOI. This article is (C) Wiley and permission has been granted for this version to appear in e-Publications@Marquette. Wiley does not grant permission for this article to be further copied/distributed or hosted elsewhere without the express permission from Wiley. 
NOT THE PUBLISHED VERSION; this is the author's final, peer-reviewed manuscript. The published version may be accessed by following the link in the citation at the bottom of the page.
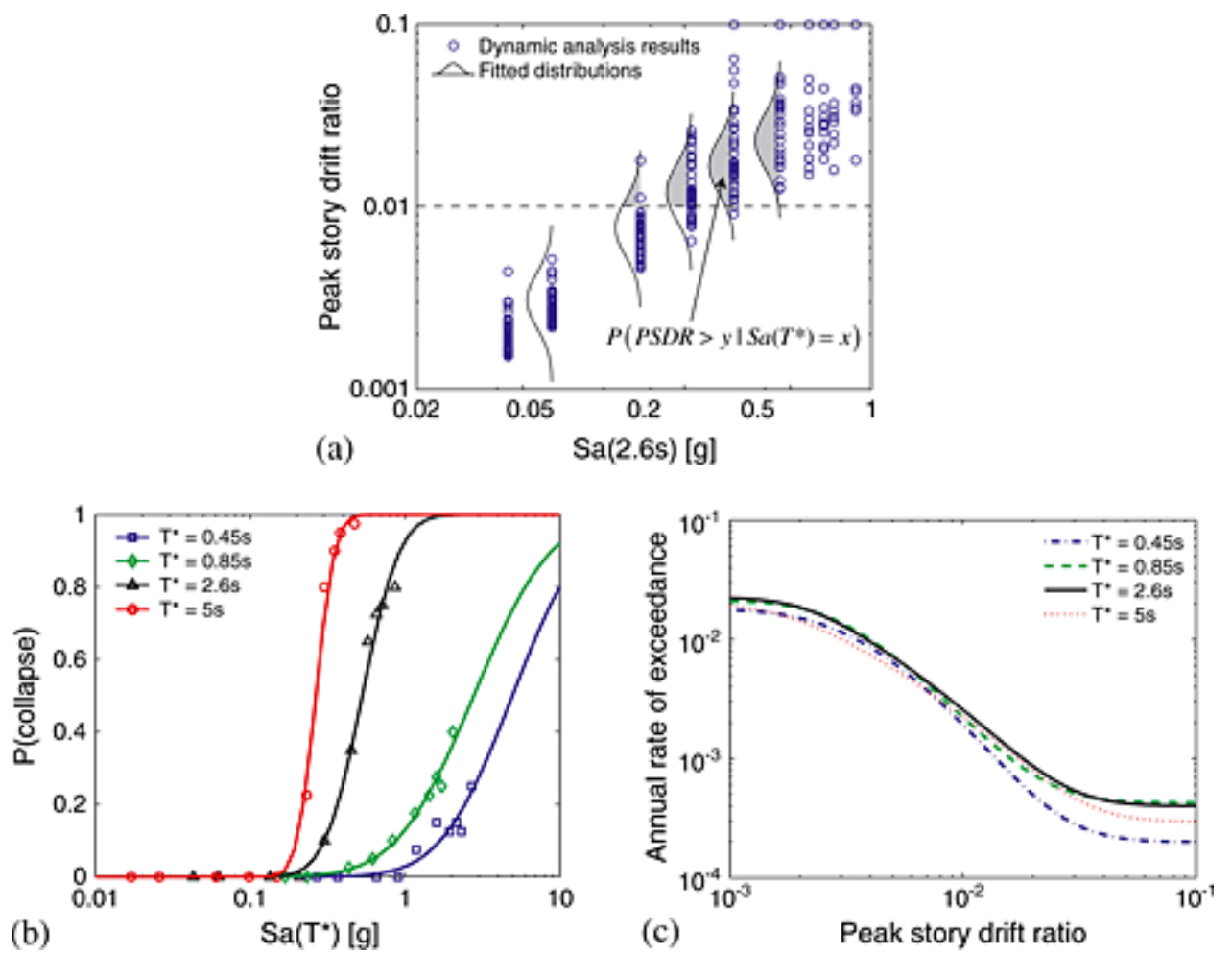

Figure 7.

(a) PSDR distribution for $\mathrm{Sa}(2.6 \mathrm{~s})$. (b) Collapse fragility for Sa at four conditioning periods. (c) Risk-based assessments of PSDR for Sa at four conditioning periods using approximate CS.
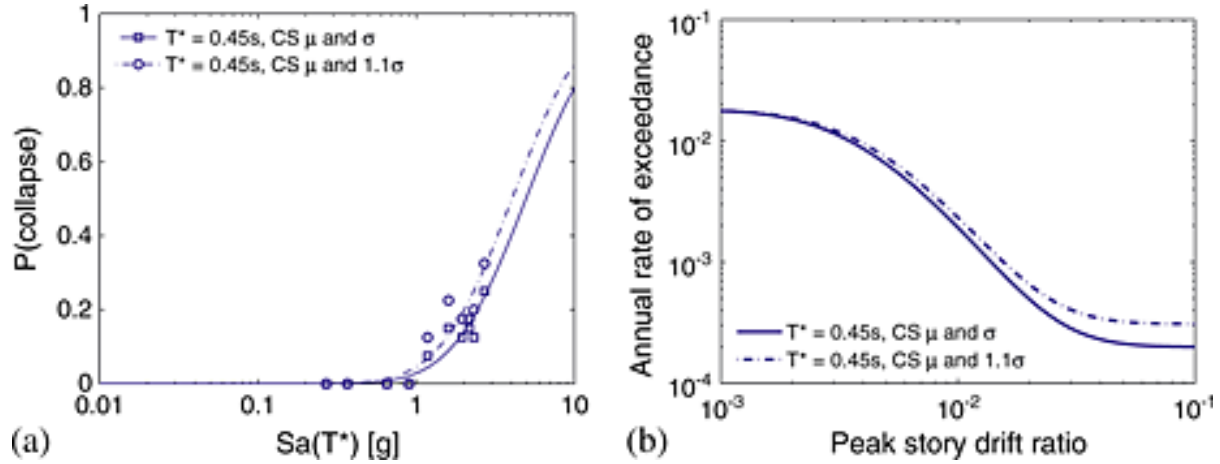

Figure 8.

(a) Collapse fragility function and (b) risk-based assessments of PSDR obtained from ground motions with an approximate conditional standard deviation and inflated conditional standard deviations for the case of $\mathrm{Sa}(0.45 \mathrm{~s})$.

Earthquake Engineering \& Structural Dynamics, Vol. 42, No. 12 (October 10, 2013): pg. 1847-1865. DOI. This article is (C) Wiley and permission has been granted for this version to appear in e-Publications@Marquette. Wiley does not grant permission for this article to be further copied/distributed or hosted elsewhere without the express permission from Wiley. 
NOT THE PUBLISHED VERSION; this is the author's final, peer-reviewed manuscript. The published version may be accessed by following the link in the citation at the bottom of the page.

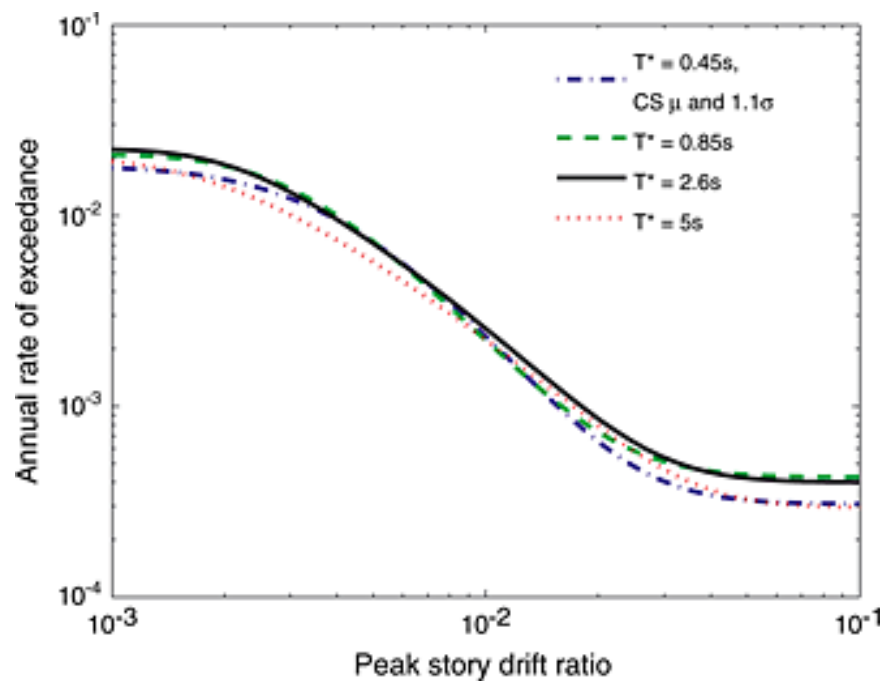

Figure 9.

Risk-based assessments of PSDR obtained with four choices of $T^{*}$ using an inflated conditional standard deviation for the case of $\mathrm{Sa}(0.45 \mathrm{~s})$.
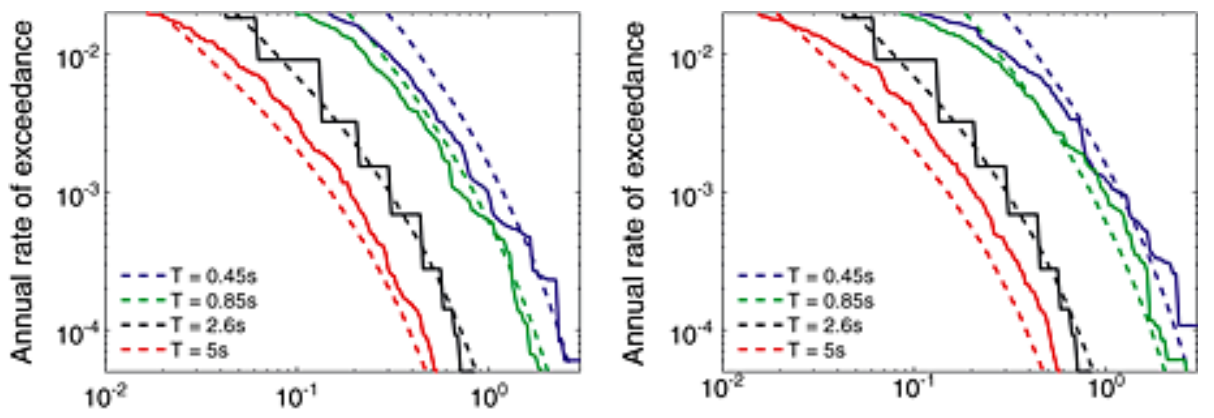

(a)

(b)

$\mathrm{Sa}(\mathrm{T})[g]$
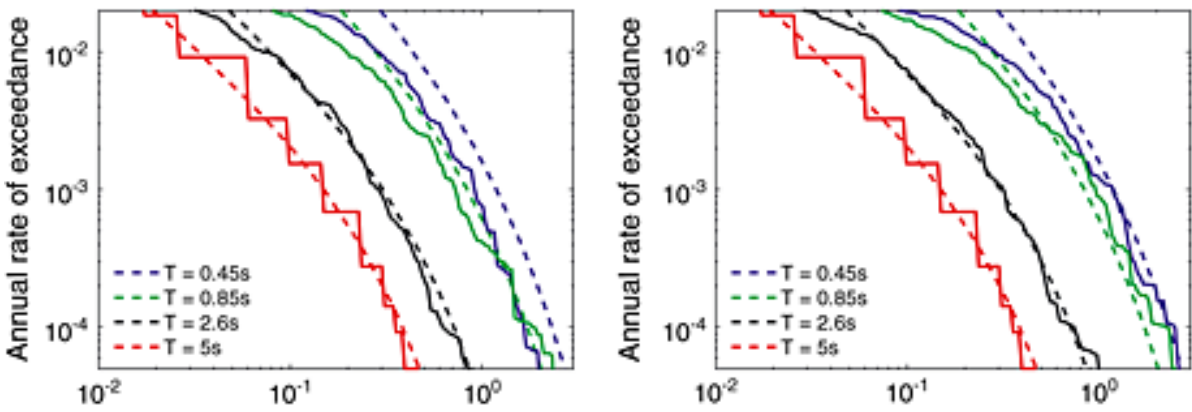

(c)

$\mathrm{Sa}(\mathrm{T})[\mathrm{g}]$

(d)

$\mathrm{Sa}(\mathrm{T})[\mathrm{g}]$

Figure 10.

Sa distribution at four periods for ground motions selected at (a) $T^{*}=2.6 \mathrm{~s}$, to match the CS $\mu$ and $\sigma$; (b) $T^{*}=2.6 \mathrm{~s}, \operatorname{CS} \mu$ and $1.3 \sigma$; (c) $T^{*}=5 \mathrm{~s}, \operatorname{CS} \mu$ and $\sigma$; and (d) $T^{*}=5 \mathrm{~s}, \mathrm{CS} \mu$ and $1.3 \sigma$.

Earthquake Engineering \& Structural Dynamics, Vol. 42, No. 12 (October 10, 2013): pg. 1847-1865. DOI. This article is (C) Wiley and permission has been granted for this version to appear in e-Publications@Marquette. Wiley does not grant permission for this article to be further copied/distributed or hosted elsewhere without the express permission from Wiley. 
NOT THE PUBLISHED VERSION; this is the author's final, peer-reviewed manuscript. The published version may be accessed by following the link in the citation at the bottom of the page.

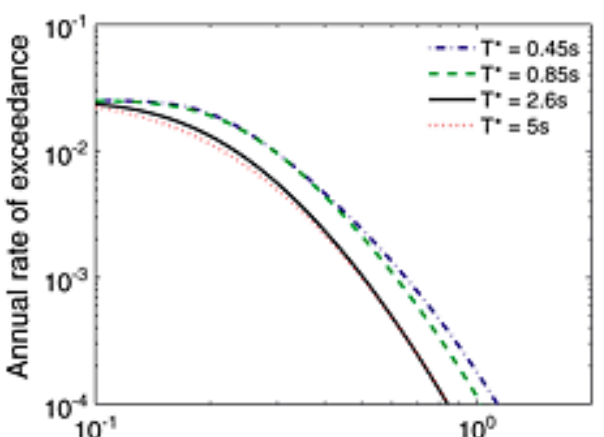

(a)

Peak floor acceleration [g]

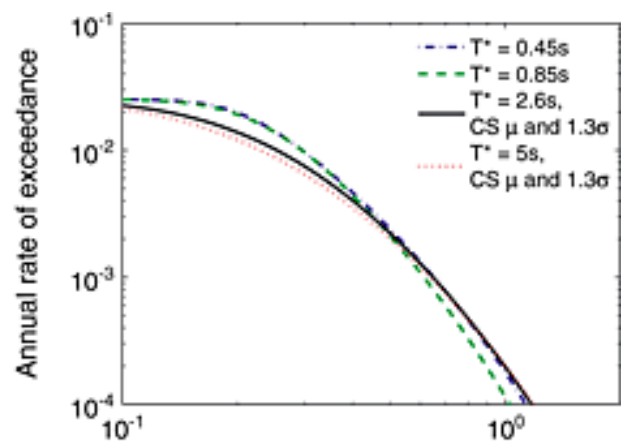

(b)

Peak floor acceleration [g]

Figure 11.

Risk-based assessments of PFA obtained with four choices of $T^{*}$ using (a) an approximate conditional standard deviation and (b) an inflated conditional standard deviation for the cases of Sa (2.6s) and Sa (5s).

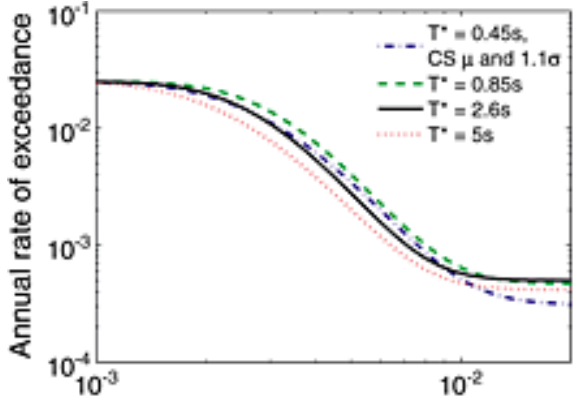

(a)

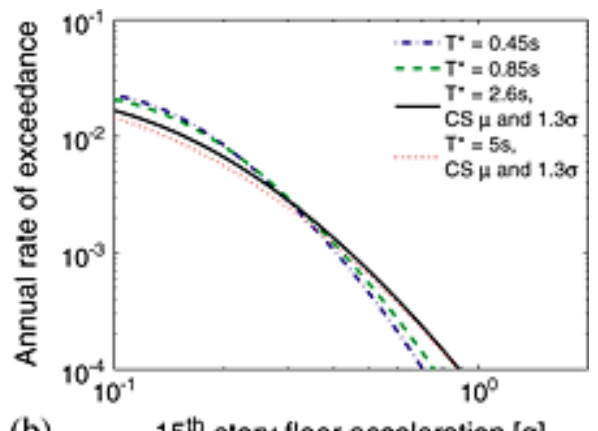

(b)

$15^{\text {th }}$-story floor acceleration [g]

Figure 12.

Rates of exceedance of drift ratios and floor accelerations on the 15th story of the building.

Table 1. Summary of selected structural response results from risk-based assessments using ground motions selected to match the CS.

\section{Risk-based performance metrics}

Conditioning periods

Types

Metrics

$0.45 \mathrm{~s}$

0.85 s

$2.6 \mathrm{~s}$

$5 \mathrm{~s}$

1. PSDR, peak story drift ratio; PFA, peak floor acceleration; EDPs, engineering demand parameters.

$\begin{array}{llllll}\text { Annual rates } & \text { PSDR }>2 \% & 6.46 \mathrm{E}-04 & 7.96 \mathrm{E}-04 & 9.42 \mathrm{E}-04 & 8.51 \mathrm{E}-04 \\ & \text { PFA }>0.5 \mathrm{~g} & 2.56 \mathrm{E}-03 & 2.28 \mathrm{E}-03 & 2.36 \mathrm{E}-03 & 2.12 \mathrm{E}-03 \\ & \text { Collapse } & 3.12 \mathrm{E}-04 & 4.66 \mathrm{E}-04 & 5.02 \mathrm{E}-04 & 4.18 \mathrm{E}-04 \\ 10 \% \text { in 50-year EDPs } & \text { Median PSDR } & 0.011 & 0.012 & 0.012 & 0.011 \\ & \text { Median PFA } & 0.529 & 0.509 & 0.521 & 0.500\end{array}$

Earthquake Engineering \& Structural Dynamics, Vol. 42, No. 12 (October 10, 2013): pg. 1847-1865. DOI. This article is (C) Wiley and permission has been granted for this version to appear in e-Publications@Marquette. Wiley does not grant permission for this article to be further copied/distributed or hosted elsewhere without the express permission from Wiley. 